Modal behavior of a reduced scale pump-turbine impeller. Part 1: Experiments

This article has been downloaded from IOPscience. Please scroll down to see the full text article.

2010 IOP Conf. Ser.: Earth Environ. Sci. 12012116

(http://iopscience.iop.org/1755-1315/12/1/012116)

View the table of contents for this issue, or go to the journal homepage for more

Download details:

IP Address: 193.226.8.90

The article was downloaded on 03/09/2010 at 07:17

Please note that terms and conditions apply. 


\title{
Modal behavior of a reduced scale pump-turbine impeller. Part 1: Experiments
}

\author{
X Escaler ${ }^{1}$, J K Hütter ${ }^{1}$, E Egusquiza ${ }^{1}$, M Farhat ${ }^{2}$ and F Avellan ${ }^{2}$ \\ ${ }^{1}$ Center for Industrial Diagnostics, Technical University of Catalonia, Av. Diagonal \\ 647, Barcelona, 08028, Spain \\ ${ }^{2}$ Laboratory for Hydraulic Machines, Ecole Polytechnique Fédérale de Lausanne, Av. \\ de Cour 33 bis, Lausanne, CH-1007, Switzerland, \\ E-mail: escaler@mf.upc.edu
}

\begin{abstract}
An experimental investigation has been carried out to quantify the effects of surrounding fluid on the modal behavior of a reduced scale pump-turbine impeller. The modal properties of the fluid-structure system have been obtained by Experimental Modal Analysis (EMA) with the impeller suspended in air and inside a water reservoir. The impeller has been excited with an instrumented hammer and the response has been measured by means of miniature accelerometers. The Frequency Response Functions (FRF's) have been obtained from a large number of impacting positions in order to ensure the identification of the main mode shapes. As a result, the main modes of vibration have been well characterized both in air and in water in terms of natural frequency, damping ratio and mode shape. The first mode is the 2 Nodal Diameter (ND), the second one is the 0ND and the following ones are the 3ND coupled with the 1ND. The visual observation of the animated mode shapes and the level of the Modal Assurance Criterion (MAC) have permitted to correlate the homologous modes of vibration of the fluid-structure system in air and in water. From this comparison the added mass effect on the natural frequencies and the fluid effect on the damping ratios have been quantified for the most significant modes. With the surrounding water, the natural frequencies decrease in average by $10 \%$. On the other hand, the damping ratios increase in average by $0.5 \%$. In any case, the damping ratio appears to decrease with the frequency value of the mode.
\end{abstract}

\section{Introduction}

Modern hydropower plants for energy storage during nighttime and energy release during peak time consist of reversible pump-turbine units. These hydraulic machines are designed with high power concentration because they operate under high heads and they rotate at fast speeds. As a result, the rotor stator interaction (RSI) is found to be a strong source of excitation that acts on the rotating impeller. The RSI has been investigated from an experimental point of view by several authors in pump diffusers (Arndt et al. [1], Qin and Tsukamoto [2], Wang and Tsukamoto [3]) and in pump-turbines (Franke et al. [4]). Theoretical analyses to predict the RSI have also been conducted like the ones from Rodriguez et al. [5] for a pump-turbine and by Xiao et al. [6] for a Francis turbine.

Nevertheless, attention must be taken when the characteristics frequencies of RSI are close to a natural frequency of the impeller and resonance conditions are achieved. In this case, large vibrations due to the amplified response of the structure are a common cause of impeller fatigue failure. In order to avoid such situation, an adequate prediction of the dynamic response of the impeller surrounded by water is of prime importance during the design stage. Both the added mass effect and the damping under operating conditions should be measured or simulated which is very difficult due to the complexity of the fluid-structure system. For example, in operating conditions the impeller is continuously surrounded by flowing fluid and there are very narrow boundaries particularly in the regions of the seals where the effects are enhanced.

Up to now, only the effect of still fluid has been determined in simple structures. For instance, the added mass effect has been obtained with analytical methods in submerged cantilever plates by Liang et al. [7] and Jeong et al. [8]. But for more complex structures such as impellers or runners, finite element models must be used. In this sense, a numerical simulation of a real Francis turbine was carried out by Dubas and Schuch [9] but 
unfortunately no experiment was done to validate it. An experimental validation was possible with the work of Rodriguez et al. [10] and Liang et al. [11] who measured and simulated respectively the added mass effect on a Francis turbine reduced scale runner. Nevertheless, the geometry of a pump-turbine impeller differs from that of a Francis runner. The blade widths are larger and the predominant modes are expected in axial direction instead of radial direction. Thus, the existing results for Francis can only be extrapolated to some extent. Consequently, an analogous procedure is proposed now for the pump-turbine geometry.

In this paper, the results from an experimental modal analysis (EMA) are presented which intend to characterize the effects of the surrounding water on the modal response of a pump-turbine reduced scale impeller. The experiments have been conducted with the structure suspended as a free body both in air and in water. The comparison of both sets of results has permitted to identify the main modes of vibrations and to estimate the added mass and damping effects of the surrounding fluid. This work has been used to validate the corresponding numerical simulations which are presented in the second part of this paper (Valero et al. [12]).

\section{Experimental set-up}

The reduced scale pump-turbine impeller is a bronze structure which is not a single body but an assembled structure of independents segments or parts. It consists of nine axisymmetric blades which are bolted between the crown and the band. The geometry is shown in Fig. 1.

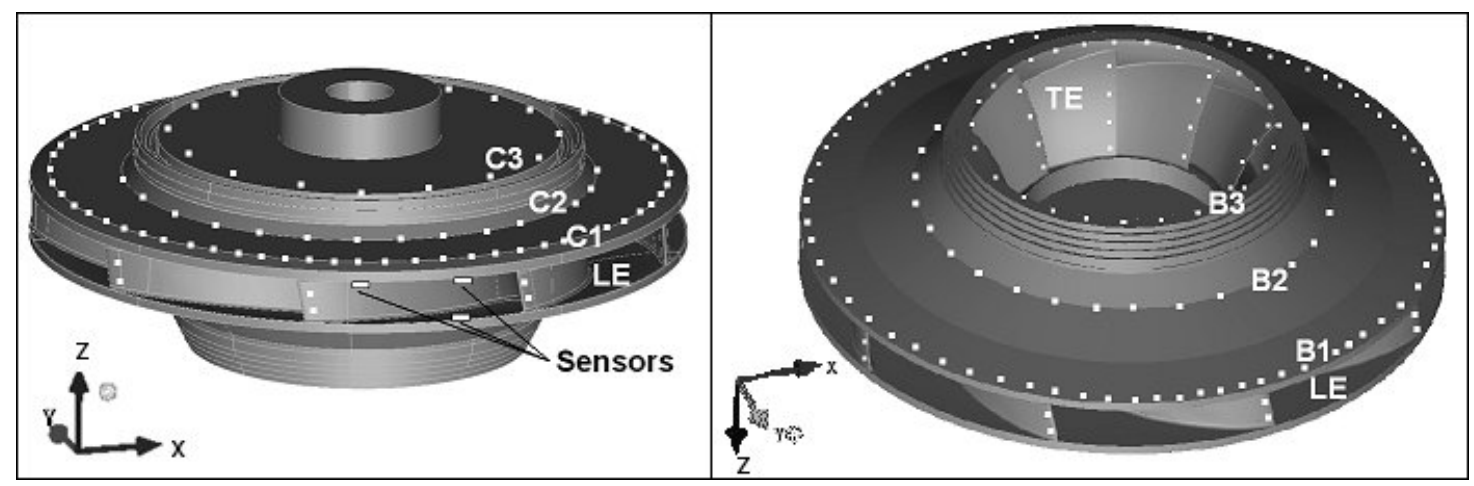

Fig. 1 Top (left) and bottom (right) views of the impeller

For the EMA the impeller has been suspended in air and in water by a rope. The tests with the impeller submerged in water have been conducted with the help of a 700x700x514mm reservoir as outlined in Fig. 2. The minimum vertical distance of the impeller to the free surface has been taken of $82 \mathrm{~mm}$ which minimizes the influence of the free surface on the damping as recommended by Rodriguez et al. [10].

An instrumented force hammer Dytran type 5800A3 has been used to excite the impeller. Three piezoelectric low mass accelerometers Brüel \& Kjaer type 4394 have been used to measure the vibration response to the impulsive force excitations. Two of them have been located beneath the crown and the other one in the band, always orientated in axial direction (see left of Fig. 1).

A Brüel \& Kjær PULSE platform has been used to acquire and record the signals. The signals have been treated to calculate the averaged Frequency Response Functions (FRF) for all the excitation positions. Then, the set of FRF's has been exported to ME'scopeVES software which has been used to extract the modal parameters and to animate the mode shapes.

\section{Test procedure}

The rowing hammer technique has been used for the measurements. The hammer has been moved around the structure to excite the degrees of freedom (DOF) needed to well characterize the dynamic behavior meanwhile the accelerometers have been kept fixed to the structure.

A preliminary numerical simulation of the impeller geometry has been used to identify the frequency band of interest and the regions with largest deformations for the expected mode shapes. From these results, it has been observed that most of the modes show maximum deformation in the tip of the band and the crown in axial direction. Consequently, the impeller has been impacted on a total of 384 DOF's. On the crown, several DOF's located along three circumferences of different diameters have been excited in axial direction (see $\mathrm{C} 1, \mathrm{C} 2$ and C3 on Fig. 1). On the band, the DOF's on the two external circumferences (see B1 and B2) have been excited in 
axial direction and the ones in the inner circle (see B3) in radial direction. On each blade, two DOF's on the leading edge (see LE) and four DOF's on the trailing edge (see TE) have also been impacted in a direction close to the radial coordinate. The frequency baseband has been selected up to $3200 \mathrm{~Hz}$ and the frequency resolution has been $0.5 \mathrm{~Hz}$. For the force signal, a transient window has been applied. For the acceleration signals, exponential windows have been used to minimize leakage effects.

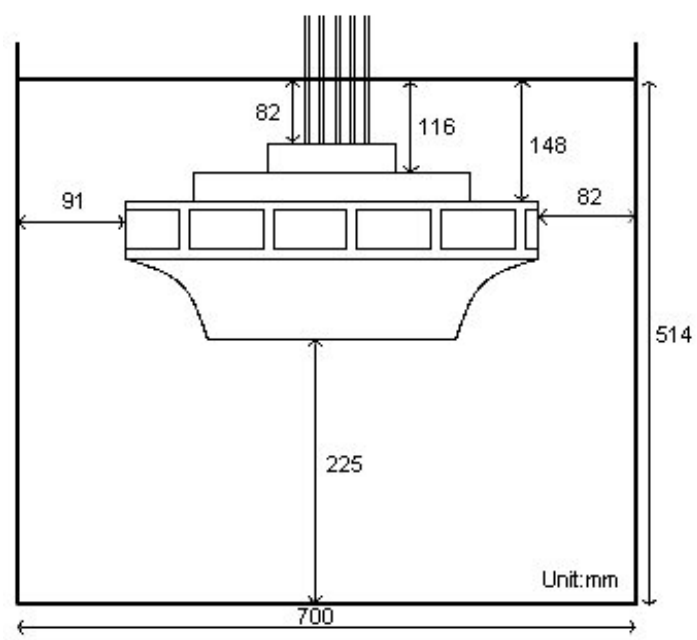

Fig. 2 Outline of impeller inside the reservoir

Each inertance $\mathrm{FRF}\left[\mathrm{ms}^{-2} / \mathrm{N}\right]$ between the excitation force signal and the induced response acceleration signal has been computed and averaged for five impacts. The independence of the acquired data from the measuring system and the repeatability of the results have been checked prior to the final tests. The reciprocity of the structure has also been checked. From the multiple reference sets of FRF's, the natural frequencies, the damping ratios and the residues or mode shape components have been estimated. The Multiple Mode Indicator Function (MMIF) has been calculated to determine the number of modes in the frequency band. This method is especially useful to identify closely coupled modes or repeated roots with the same frequency.

The comparison of modes in air and in water has been based on the Modal Assurance Criterion (MAC) which provides a measure of the least-squares deviation from the straight line correlation between two modes. Its value can range from 0 to 1 . A value close to zero indicates no linearity between the modes and a value close to unity indicates that the modes are consistent (Allemang [13]).

Finally, in order to quantify the added mass effect for a given mode shape, the reduction of the modal frequency between the system in air and in water has been used. For that, the frequency reduction ratio (FRR) has been defined as follows:

$$
F R R=\frac{f_{a}-f_{w}}{f_{a}}
$$

where $f_{a}$ is the frequency value of the mode in air and $f_{w}$ the frequency of the corresponding mode in water. Regarding the damping, the damping ratio, $\zeta$, has been calculated defined as follows:

$$
\zeta=\frac{c}{c_{c}}
$$

where $c$ is the damping constant and $c_{c}$ is the critical damping constant. To calculate the fluid effects on the damping ratio, the absolute damping variation (ADV) has been defined as follows:

$$
A D V=\zeta_{w}-\zeta_{a}
$$

where $\zeta_{a}$ is the damping ratio in air and $\zeta_{w}$ is the damping ratio in water. 


\section{Results and discussion}

The similarity of the axisymmetric impeller structure to a couple of circular discs connected by the blades makes it adequate to classify its modes using the number of nodal diameters (ND). For instance, some pictures corresponding to the animations of 2ND mode shape in air are shown in Fig. 3. These animations serve to characterize the modes and to validate the mode correlation between air and water results quantified according to the MAC. Two different kinds of animations have been used as exemplified in Fig. 3. The first one (left of Fig. 3 ) represents the interpolated deformation of the whole structure in four different views corresponding to the topview, the 3D-view and two lateral views. The second type of animation (right of Fig. 3) shows the measured DOF's in axial direction along lines that represent the developed circles. The three top lines correspond to the crown circles $\mathrm{C} 1, \mathrm{C} 2$ and $\mathrm{C} 3$; and the two bottom lines correspond to the band circles B1 and B2. The lines in the front are the circles $\mathrm{C} 1$ and $\mathrm{B} 1$ at the periphery of the impeller and the lines in the background correspond to the inner circles. Following this type of animation, the mode shapes corresponding to 0ND, 1ND, 3ND, 4ND, 22ND and 7ND are shown in Fig. 4. In particular, the second mode encountered with a 2ND pattern has been called 2-2ND.

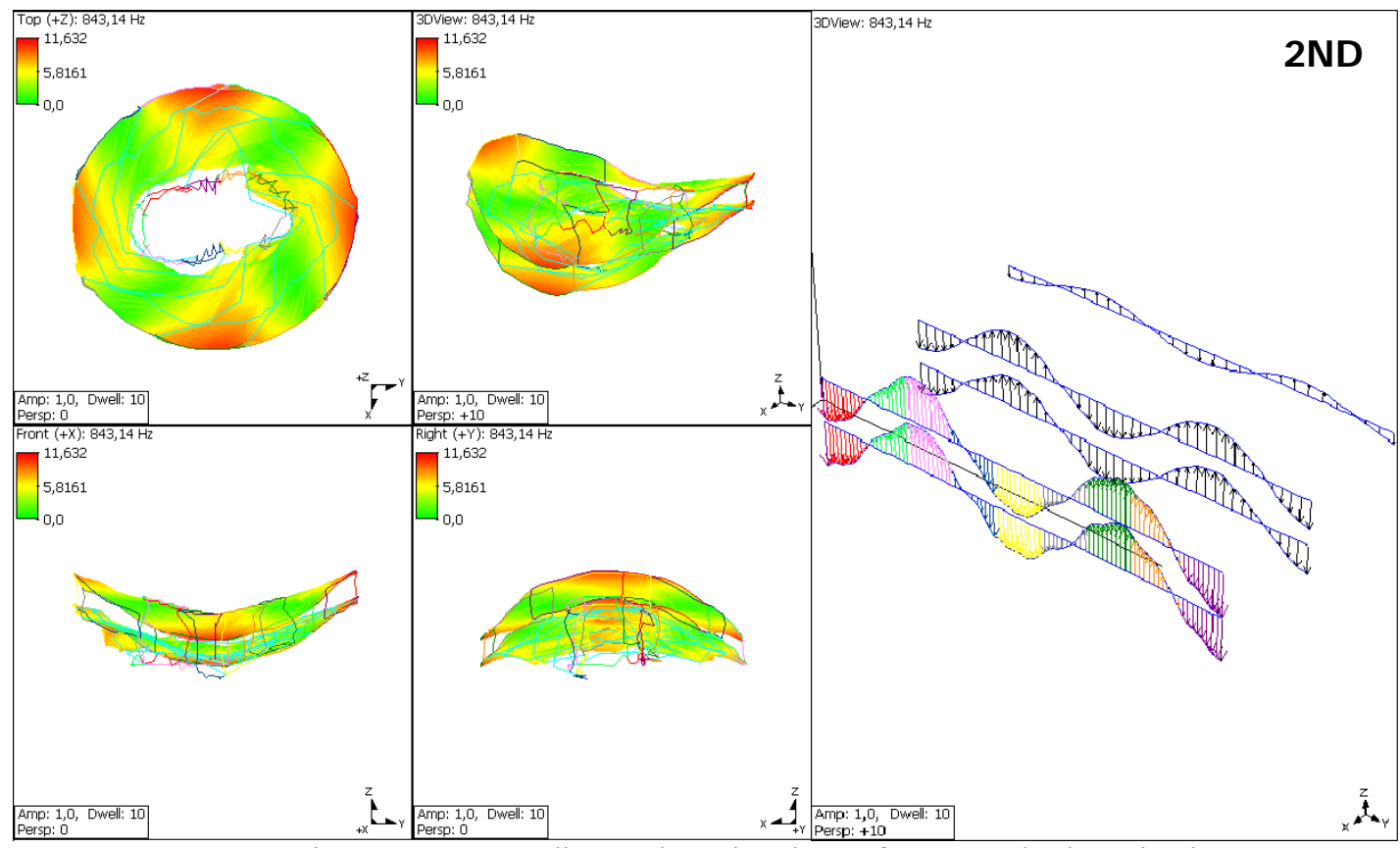

Fig. 3 Pictures corresponding to the animations of 2ND mode shape in air

On the top of Fig. 5 the MMIF's corresponding to air condition are shown. It can be observed that the first two modes correspond to the 2ND and the 0ND, which appear well separated. Afterwards the 1ND and the 3ND are identified very close to each other forming a coupled mode of vibration. Then, a 4ND which is close to a 22ND is also found. The frequency range from about 2200 to $2800 \mathrm{~Hz}$ presents a high modal density. Some of the modes in this range cannot be clearly identified because their mode shapes are complicated. For example, the 5ND and the 6ND are difficult to identify. Finally, the 7ND mode can be clearly found at the end of the frequency band.

For the impeller in water, as observed at the bottom of Fig. 5, the frequencies of the corresponding modes are lower and almost all of them keep the same order than in air. Firstly, the 2ND and the 0ND can be found. Secondly, the previously coupled modes 3ND and 1ND are now more separated but they have swapped their relative positions. Furthermore, the modes 4ND and 2-2ND are now getting even closer so that they are difficult to be distinguished. For them, the mode shape video shows the two movements completely superposed. Finally, two modes corresponding to $7 \mathrm{ND}$ and $8 \mathrm{ND}$ are clearly distinguishable. The $8 \mathrm{ND}$ is now in the measurement range up to $3200 \mathrm{~Hz}$. Again, the 5ND and the 6ND are difficult to identify. 


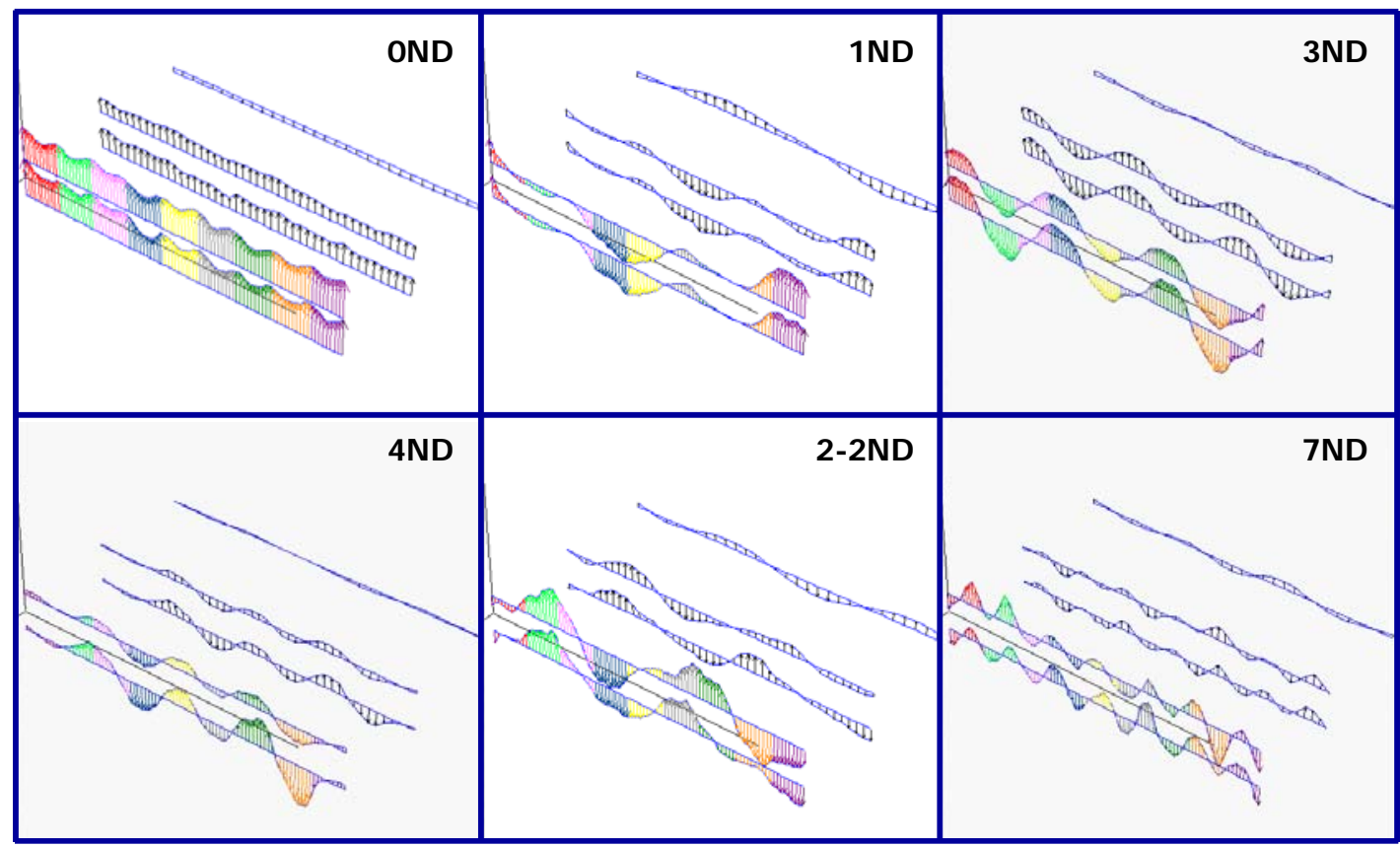

Fig. 4 Pictures of the animations corresponding to 0ND, 1ND, 3ND, 4ND, 2-2ND, 7ND mode shapes in air

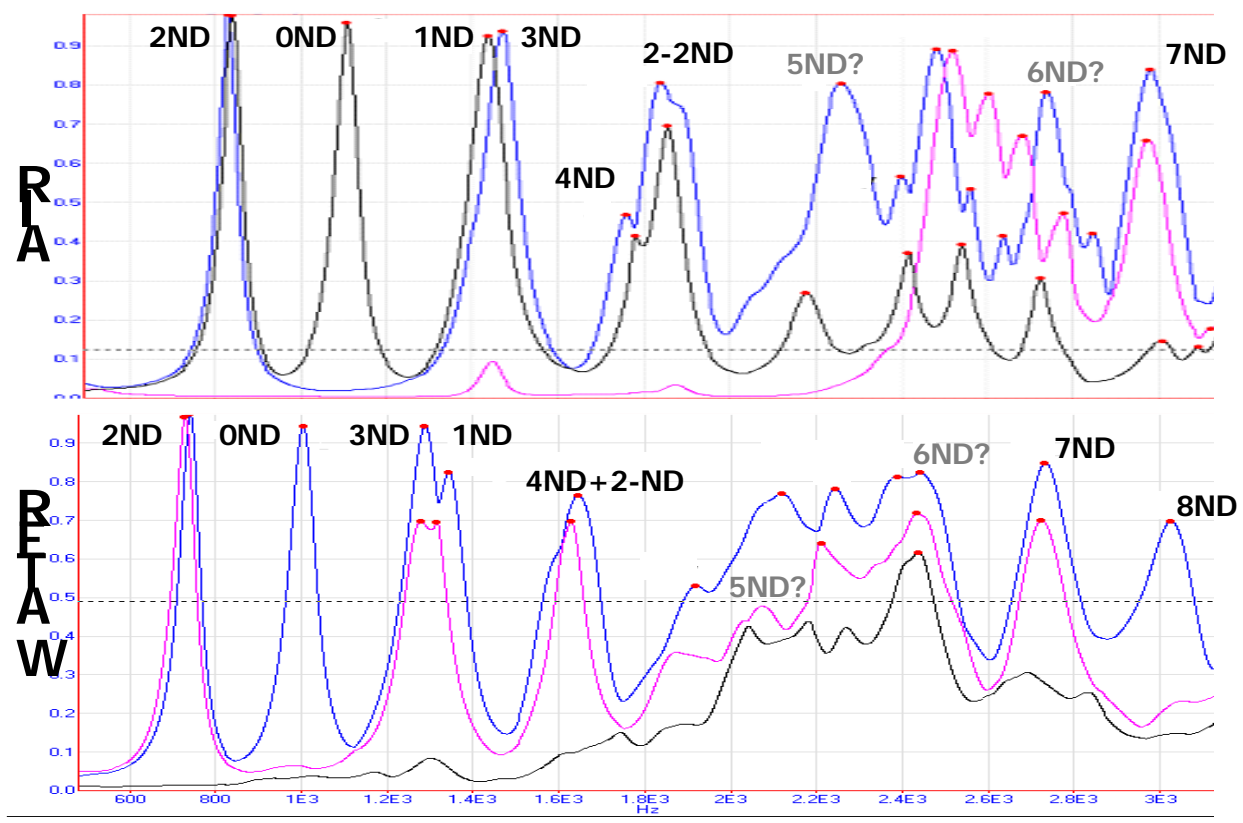

Fig. 5 MMIF's from the experiments carried out in air (top) and water (bottom)

Regarding the level of correlation between modes in air and in water, for the first two modes, 2ND and 0ND, the MAC value is higher than 0.9 and thus it confirms that their mode shapes are almost identical. For the 3ND and $1 \mathrm{ND}$, the MAC value is about 0.8 and 0.5 respectively. For the rest of the modes, the values drop more but their resemblance has been checked with the mode shape animations comparison.

In general, the natural frequency values of the repeated roots present differences from about 5 to $40 \mathrm{~Hz}$. Therefore, the mean value has always been considered for simplification. For the rest of the parameters, also averaged values are indicated. All the natural frequencies, damping ratios, FRR's and ADV's in air and in water are listed in Table 1. 
As it can be observed, the added mass effect of the surrounding water has leaded to a decrease of the frequencies for all the modes. The average FRR for all the modes is of about $10 \%$. The minimum value of about $7 \%$ corresponds to $1 \mathrm{ND}$ and the maximum value of about $13 \%$ to $3 \mathrm{ND}$. The values of FRR have been plotted in Fig. 6.

Table 1 Averaged natural frequencies, damping ratios, FRR's and ADV's in air and in water.

\begin{tabular}{|c|c|c|c|c|c|c|}
\hline \hline Mode (ND) & $f_{a}$ & $f_{w}$ & $F R R$ & $\zeta_{a}$ & $\zeta_{w}$ & $A D V$ \\
\hline 2ND & 838 & 735 & 0,12 & 0,034 & 0,040 & 0,006 \\
\hline 0ND & 1111 & 1006 & 0,10 & 0,030 & 0,037 & 0,007 \\
\hline 3ND & 1463 & 1279 & 0,13 & 0,032 & 0,041 & 0,009 \\
\hline 1ND & 1439 & 1342 & 0,07 & 0,030 & 0,031 & 0,001 \\
\hline 4ND & 1811 & 1630 & 0,10 & 0,032 & 0,031 & $-0,001$ \\
\hline 2-2ND & 1861 & 1630 & 0,12 & 0,022 & 0,031 & 0,009 \\
\hline 5ND & 2282 & 2103 & 0,08 & 0,025 & 0,026 & 0,001 \\
\hline 6ND & 2769 & 2464 & 0,11 & 0,014 & 0,016 & 0,002 \\
\hline 7ND & 3003 & 2741 & 0,09 & 0,015 & 0,026 & 0,011 \\
\hline
\end{tabular}

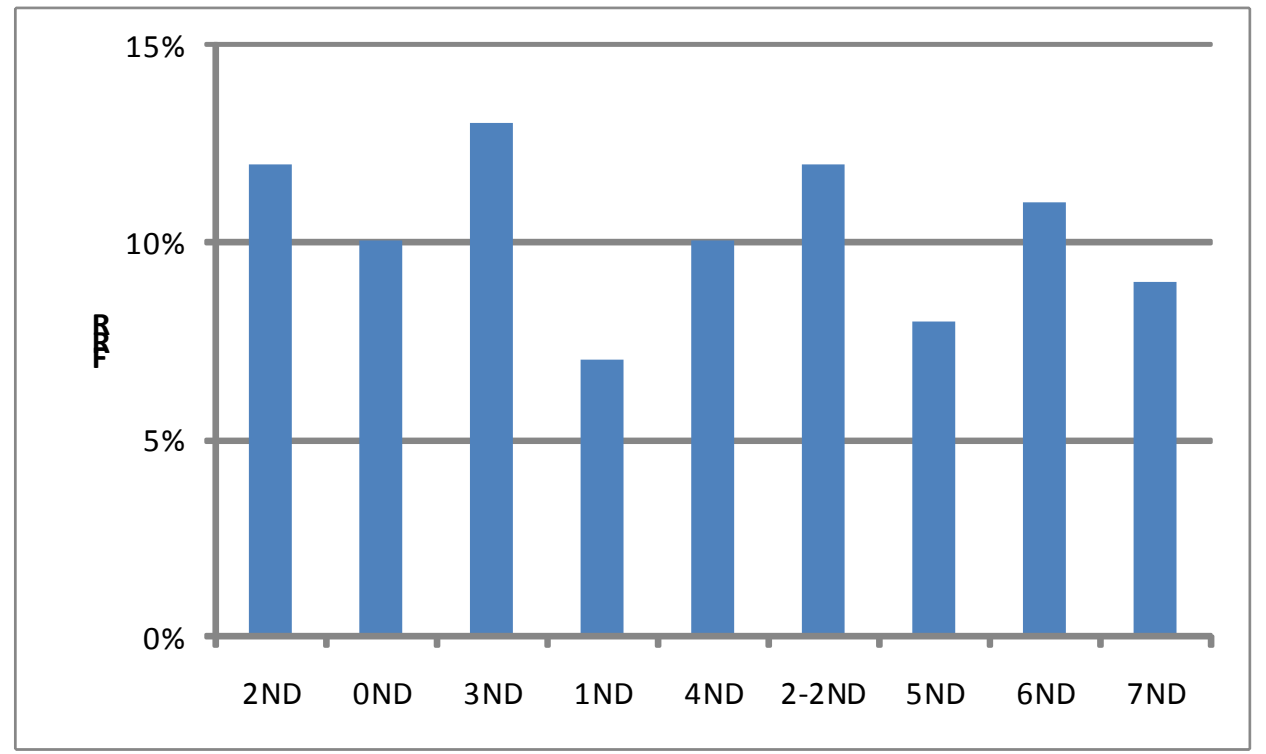

Fig. 6 Frequency reduction ratio for each mode

The damping ratios have been compared between air and water for all the modes. First of all, these results have been plotted versus frequency in Fig. 7. It is clearly observed that damping decreases with frequency both with air and with water. Moreover, the calculated linear regressions of the two sets of points indicate that, in general, the fluid tends to increase the damping. It must be noted that the linear trend for air shows a higher coefficient of determination $R^{2}$ than for water $(0.8$ for 0.7$)$.

Finally, the ADV values for each mode have been plotted in Fig. 8. In average, there is an increase of damping of about $0.5 \%$ considering all the modes. The maximum damping increase is found for 7ND with a value of about $1.1 \%$. On the other hand, the minimum values are found for modes 1ND and 4ND. For them the damping appears to remain almost constant or even to decrease with the presence of water. But in fact, these results must be taken with care because they correspond to modes which are closely coupled with other modes. Consequently, there might be a significant error in the calculation of the damping ratio. 


\section{Conclusions}

The modal properties of a reduced scale pump-turbine impeller have been determined in free conditions in air and submerged in water by means of an experimental modal analysis. The natural frequencies, damping ratios and mode shapes have been identified, correlated and compared.

The added mass effect decreases the natural frequencies of the modes in average by a $10 \%$. Nevertheless, slight differences are observed depending on the mode shape.

The effect of the water tends to increase the damping ratio of the modes in average by a $0.5 \%$. Nevertheless, slight differences are observed depending on the mode shape. Finally, it has been observed that the damping tends to decrease with the modal frequency.

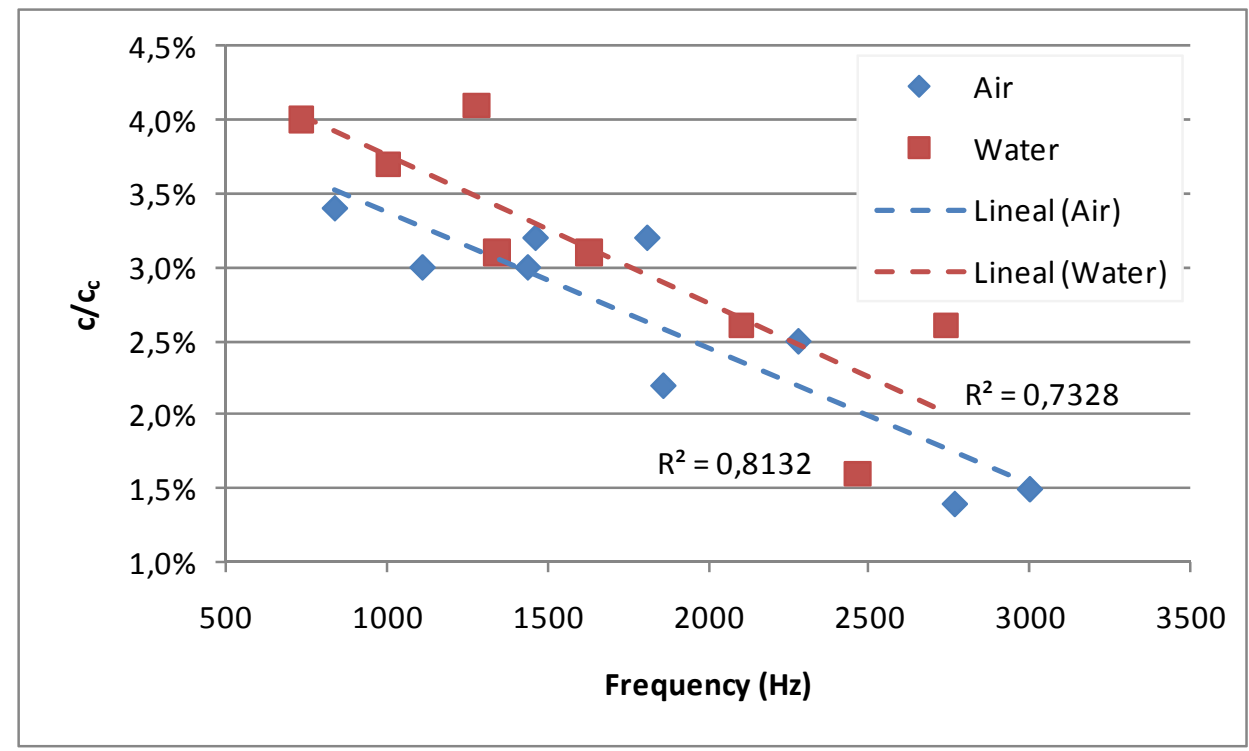

Fig. 7 Damping ratio as a function of frequency

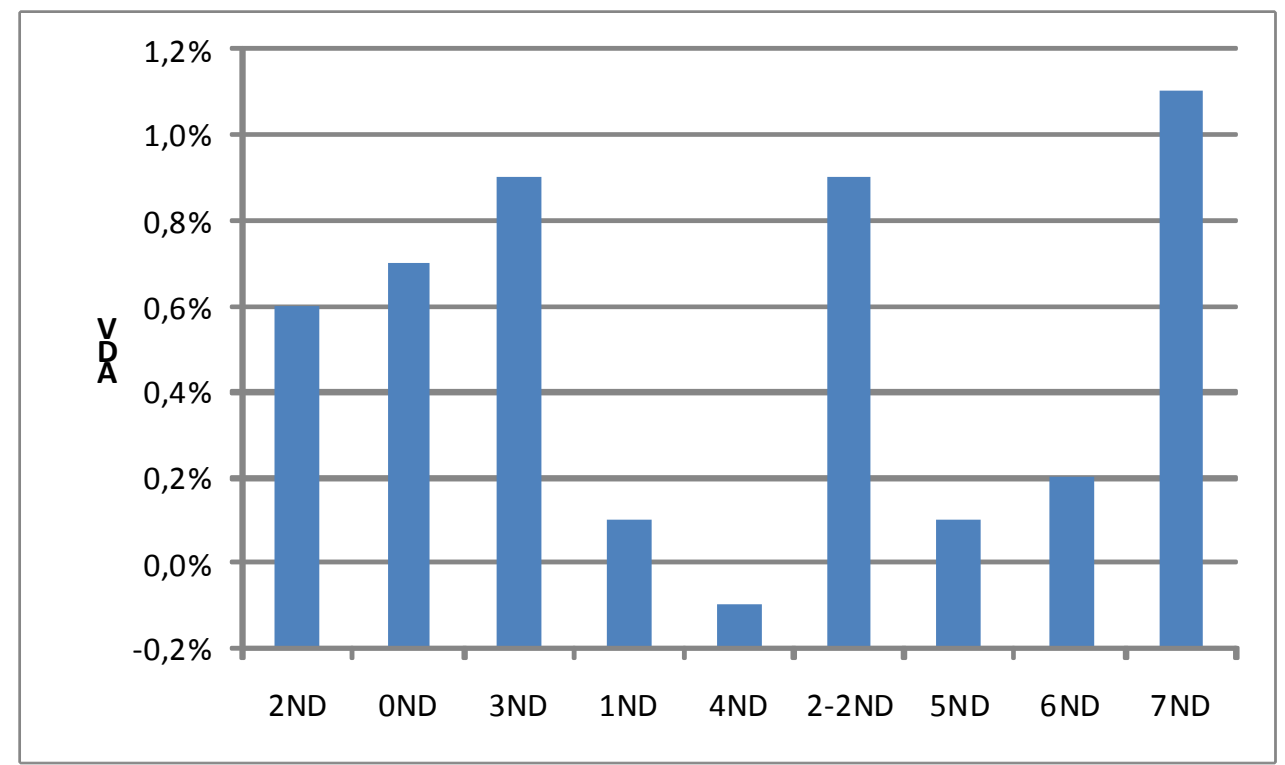

Fig. 8 Absolute damping variation from air to water for each mode 


\section{Acknowledgments}

This research has been carried out as a part of the Hydrodyna Phase II research project. The authors would like to acknowledge the LMH (EPFL) of Lausanne (Switzerland) and all the industrial partners of the project for their collaboration.

\section{Nomenclature}

$\begin{array}{llll}\text { ADV } & \text { Absolute damping variation } & \text { RSI } & \text { Rotor stator interaction } \\ \text { DOF } & \text { Degree of freedom } & c & \text { Damping constant [Ns } / \mathrm{m}] \\ \text { EMA } & \text { Experimental modal analysis } & c_{c} & \text { Critical damping constant [Ns/m] } \\ \text { FRF } & \text { Frequency response función } & f & \text { natural frequency }[\mathrm{Hz}] \\ \text { FRR } & \text { Frequency reduction ratio } & f_{a} & \text { natural frequency in air } \\ \text { MAC } & \text { Modal assurance criterion } & f_{w} & \text { natural frequency in water } \\ \text { MMIF } & \text { Multiple mode indicator function } & R^{2} & \text { coefficient of determination } \\ \text { ND } & \text { Nodal diameter } & \zeta & \text { Damping ratio }\left(=c / c_{c}\right) \\ \zeta_{a} & \text { Damping ration in air } & \zeta_{w} & \text { Damping ration in water }\end{array}$

\section{References}

[1] Arndt N, Acosta A J, Brennen C E and Caughey T K 1989 Rotor-Stator Interaction in a Diffuser Pump J. of Turbomachinery $111213-21$

[2] Qin W and Tsukamoto H 1997 Theoretical Study of Pressure Fluctuations Downstream of a Diffuser Pump Impeller - Part1: Fundamental Analysis on Rotor-Stator Interaction J. of Fluids Engin. $119647-52$

[3] Wang H and Tsukamoto H 2001 Fundamental Analysis on Rotor-Stator Interaction in a Diffuser Pump by Vortex Method J. of Fluids Engin 123 737-47

[4] Franke G, Fisher R, Powell C, Seidel U and Koutnik J 2005 On Pressure Mode Shapes Arising from Rotor/Stator Interactions Sound and Vibration March pp 14-18

[5] Rodriguez C G, Egusquiza E and Santos I F 2007 Frequencies in the Vibration Induced by the Rotor Stator Interaction in a Centrifugal Pump Turbine J. of Fluids Engin.129(11) 1428-35

[6] Xiao R, Wang Z and Luo Y 2008 Dynamic Stresses in a Francis Turbine Runner Based on Fluid-Structure Interaction Analysis Tsinghua Science and Technology 13(5) 587-92

[7] Liang C C, Liao C C, Tai Y S and Lai W H 2001 The Free Vibration Analysis of Submerged Cantilever Plates Ocean Engin. 28 pp 1225-45

[8] Jeong K H, Yoo G H and Lee S C 2004 Hydroelastic Vibration of Two Identical Rectangular Plates J. of Sound and Vibration 272(3-5) 539-55

[9] Dubas M and Schuch, M 1987 Static and Dynamic Calculation of a Francis Turbine Runner with Some Remarks in Accuracy Computer and Structures 27(5) 645-55

[10] Rodriguez C G, Egusquiza E, Escaler X, Liang Q W and Avellan F 2006 Experimental Investigation of Added Mass Effects on a Francis Turbine Runner in Still Water J. of Fluids and Structures 22 699-712

[11] Liang QW, Rodriguez C G, Egusquiza E, Escaler X, Farhat M and Avellan F 2007 Numerical Simulation of Fluid Added Mass Effect on a Francis Turbine Runner Computers and Fluids 36(6) 1106-18

[12] Valero C, Huang X, Egusquiza E, Farhat M and Avellan F 2010 Modal Behaviour of a Reduced Scale Pump-Turbine Impeller. Part 2: Numerical Simulation $25^{\text {th }}$ IAHR Symp. on Hydraulic Machinery and Systems (Timisoara, Romania, September 20-24)

[13] Allemang R J 2003 The Modal Assurance Criterion - Twenty Years of Use and Abuse Sound and Vibration pp 14-21 